\title{
CHILD NEGLECT: CHILDREN LEFT UNATTENDED IN PARKED VEHICLES IN ITALY
}

\author{
P. Ferrara1, C. Zappia2, F. Sandullo2, C. Serio², A. Di Lucia2, C. Infantino2, L. \\ Semeraro 2 , M. Pulcino2, D. Saitta2, V. Sannicandro1 \\ 1 Università Cattolica del Sacro Cuore, Institute of Pediatrics, Rome, Italy. \\ 2Università Campus Bio-Medico, Service of Pediatrics, Rome, Italy. of Pediatrics, Rome, \\ Italy.
}

\section{Background and Aims}

The study investigates the incidence of children left unattended in parked motor vehicles in Italy. According to the Child Abuse and Prevention Treatment Act, this phenomenon can be considered a form of neglect. Compared to adults, children are more vulnerable: infact their exposure to warm environments could result in death from hyperthermia and heat stroke. The explanations could be that children have a high surface area body mass ratio, a less heat dissipation from the center to the periphery of the body and a less sweat production.

\section{Methods}

We have collected data from two sources. The first one was the Null of San Francisco State University, that has been used in United States since 1998, to identify hyperthermia deaths of children, and has been updated the 25th

September 2012. The second source consisted in informations aquired from newspaper indexes and news websites between 1st May, 2011 and the 31st August, 2012.

\section{Conclusion}

The study shows that between 1 May 2011 and 31 August 2012, 38 cases of childhood hyperthermia occurred due to abandonment in parked vehicles. We identified 20 males, 16 females and in 1 case the gender of the child was unidentifiable. In 4 cases the children left unattended were 2 . In $73.7 \%$ cases the children were lefted intentionally in the car, in $23.7 \%$ unintentionally, the intentionality was not clear in $2.6 \%$ cases..

\section{Results}

The study shows that between 1 May 2011 and 31 August 2012, 38 cases of childhood hyperthermia occurred due to abandonment in parked vehicles. We identified 20 males, 16 females and in 1 case the gender of the child was unidentifiable. In 4 cases the children left unattended were 2 . In $73.7 \%$ cases the children were lefted intentionally in the car, in $23.7 \%$ unintentionally, the intentionality was not clear in $2.6 \%$ cases. 